OPEN ACCESS

Edited by:

Chongyu Zhu,

Fudan University, China

Reviewed by:

Theoni K. Georgiou, Imperial College London,

United Kingdom

Marya Ahmed,

University of Prince Edward

Island, Canada

Ruijiao Dong,

Shanghai Jiao Tong University, China

*Correspondence:

Shiqi Wang

shiqi.wang@helsinki.fi

Specialty section:

This article was submitted to

Polymer Chemistry,

a section of the journal

Frontiers in Chemistry

Received: 22 December 2020

Accepted: 22 February 2021

Published: 23 March 2021

Citation:

Wang S (2021) pH-Responsive Amphiphilic Carboxylate Polymers: Design and Potential for Endosomal Escape. Front. Chem. 9:645297. doi: 10.3389/fchem.2021.645297

\section{pH-Responsive Amphiphilic Carboxylate Polymers: Design and Potential for Endosomal Escape}

\author{
Shiqi Wang * \\ Drug Research Program, Division of Pharmaceutical Chemistry and Technology, Faculty of Pharmacy, University of Helsinki, \\ Helsinki, Finland
}

The intracellular delivery of emerging biomacromolecular therapeutics, such as genes, peptides, and proteins, remains a great challenge. Unlike small hydrophobic drugs, these biotherapeutics are impermeable to the cell membrane, thus relying on the endocytic pathways for cell entry. After endocytosis, they are entrapped in the endosomes and finally degraded in lysosomes. To overcome these barriers, many carriers have been developed to facilitate the endosomal escape of these biomacromolecules. This mini-review focuses on the development of anionic pH-responsive amphiphilic carboxylate polymers for endosomal escape applications, including the design and synthesis of these polymers, the mechanistic insights of their endosomal escape capability, the challenges in the field, and future opportunities.

Keywords: pH, intracellular delivery, amphiphilicity, polymeric materials, drug delivery and targeting

\section{INTRODUCTION}

Most successfully developed biotherapeutics up to date only target extracellular receptors, because the intracellular delivery of biomacromolecules remains a key challenge (Stewart et al., 2018; van Haasteren et al., 2020). Such challenge resides in the natural barrier of plasma membranes, composed of a lipid bilayer and membrane proteins. The permeability of the plasma membrane is specifically selective. Therefore, biomacromolecular therapeutics, such as proteins, peptides, and genes, are blocked from free movement across the plasma membrane (Pei and Buyanova, 2019). Instead, these biomacromolecules are mostly internalized by endocytosis. After internalization, they are trapped in endosomes, and finally degraded within lysosomes. Thus, it is critical to develop carriers to facilitate the endosomal escape and release the payloads in cytoplasm, to maximize their therapeutic potential.

Polymer carriers for endosomal escape purposes have been developed for years. Specifically, pH-responsive polymers have attracted significant attention (Cupic et al., 2019; Deirram et al., 2019), because their endosomal escape property is activated by the $\mathrm{pH}$ differences between the extracellular physiological environment (7.4) and the acidic endosomal environment (6.0-6.8 in early endosomes, 5.0-6.0 in late endosomes, and 4.5-5.0 in lysosomes)(Mukherjee et al., 1997; Scott et al., 2014). According to the ionizable groups, there are two main $\mathrm{pH}$-responsive polymer categories: polycations and polyanions (Bazban-Shotorbani et al., 2017). Polycations have weak basic functional groups, such as amines, imidazole, and pyridine, which become positively charged when the $\mathrm{pH}$ drop below their $\mathrm{pK}_{\mathrm{a}}$. These polymers [i.e., polyethylenimine, poly( $\mathrm{L}$-lysine), poly(amino ester), poly(2-(dimethylamino)ethyl methacrylate), and polyamidoamine] can 
buffer the endosomal acidification by protonation, and cause osmotic swelling of endosomes, finally leading to endosomal rupture. The polycation induced "proton sponge" effect has long been studied, and reviewed recently (Bus et al., 2018; Vermeulen et al., 2018). In addition to the endosomal escape properties, polycations condensate genes by electrostatic interactions effectively, and thus are widely used for gene therapy (Chen et al., 2019).

Polyanions use a different strategy for endosomal escape. Typically, these polymers are negatively charged at physiological $\mathrm{pH}$. The negative charges make them repulsive to the negatively charged plasma membranes and show non-membrane lytic property (Figure 1A). However, when $\mathrm{pH}$ drops below their $\mathrm{pK}_{\mathrm{a}}$ in the endosomes, they lose the charge and become hydrophobic. The $\mathrm{pH}$-induced alterations in the overall charges, amphiphilicity, and conformation lead to enhanced interaction with endosomal membranes and finally cause membrane disruption to release the payload into the cytoplasm (Figure 1A). Compared with polycationic polymeric carriers, anionic $\mathrm{pH}-$ responsive membrane permeabilizing polymers are less toxic, because of the repulsive charges against plasma membranes
(Wang, 2018; Evans et al., 2019). Albeit less renowned, recent studies show their emerging potentials for proteins, genes, and vaccine delivery (Mukalel et al., 2018; Qiu et al., 2018; Evans et al., 2019; Jacobson et al., 2019; Kopytynski et al., 2020).

Herein, this mini-review introduces the development of polyanions with carboxylic acid pendant groups for endosomal escape applications. These polymers usually have two units to fulfill their function, carboxylic acid unit and hydrophobic unit (Figure 1B). The carboxylic acid unit is for $\mathrm{pH}$-responsiveness, and the hydrophobic unit is for enhancing the interaction with lipid membranes. These two units could be integrated in one monomer (homopolymer), or distributed on two different monomers (copolymer) (Figure 1B). Notable examples of homopolymers include poly(ethylacrylic acid) (PEAA) and poly(propylacrylic acid) (PPAA) (Figure 1C), which have been developed for two decades for gene and protein delivery. Copolymers could be developed by copolymerization of methacrylic acid (MAA) or acrylic acid (AA) as the carboxylic acid unit, and hydrophobic methacrylates (Figure 1C). Alternatively, copolymers with different backbones, such as polypeptides and pseudopeptides, could be developed

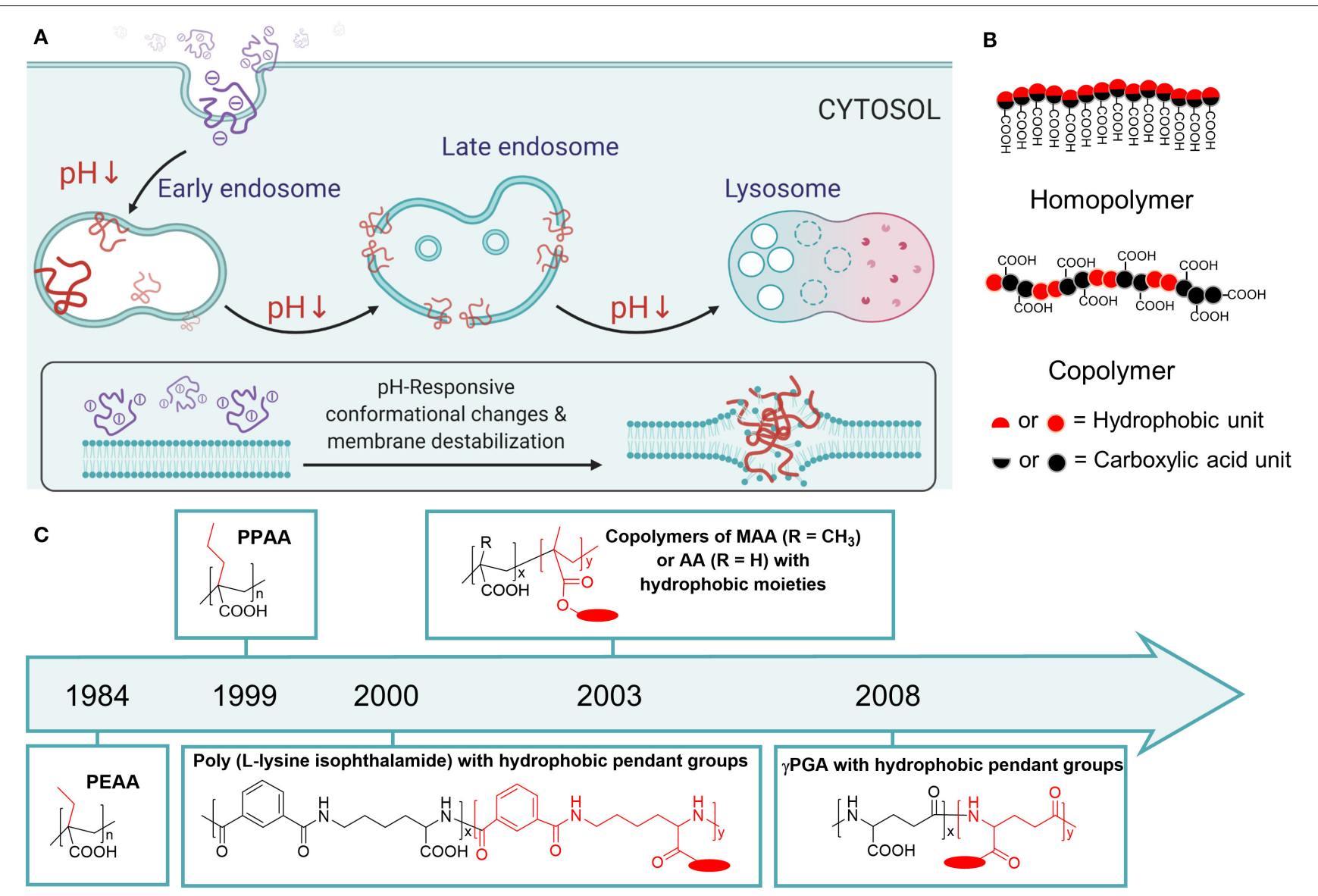

FIGURE 1 | (A) The scheme of pH-responsive membrane permeabilizing polymers and how they facilitate endosomal escape. Created by Biorender.com (B) The general design of carboxylated polyanions for endosomal escape applications. (C) Chronological development of carboxylated polymers for endosomal escape applications. The time plotted indicated the first application for $\mathrm{pH}$-dependent membrane permeabilization, instead of the first reported synthesis of the polymer. 
by post-polymerization modification of hydrophobic units (Figure 1C). In the following sections, the endosomal escape capability of these polymers and their functionalized derivatives in drug delivery applications are analyzed. Finally, the current challenges of $\mathrm{pH}$-responsive endosomal escape polyanions development are discussed, as well as the future opportunities to be exploited.

\section{AMPHIPHILIC CARBOXYLATE POLYMERS: HISTORY AND RECENT DEVELOPMENT}

\section{PEAA, PPAA, and Their Derivatives}

Amphiphilic carboxylate polymers were first found to have $\mathrm{pH}$ dependent membrane permeabilizing capability on liposomal membranes made of egg phosphatidylcholine (PC) lipids in the 1980s (Seki and Tirrell, 1984). This effect was initially studied using PEAA, which showed significant membrane disruptive activity at its $\mathrm{pK}_{\mathrm{a}}$ (6.5), without disrupting the membrane at physiological pH (Thomas and Tirrell, 1992). The membrane disruption was attributed to the $\mathrm{pH}$-dependent coil-to-globule conformational transition, evidenced by hydrodynamic size variation and the desolvation of a hydrophobic fluorescent probe pyrene (Eum et al., 1989). The uncharged polymer with globule conformation could associate with the lipid membrane and even lysed the membrane completely at high polymer/lipid ratios (Thomas et al., 1994). Although these early studies based on PEAA interaction with liposomes did not explore the $\mathrm{pH}$-dependent membrane permeabilizing effects on mammalian cells for intracellular delivery purposes, such findings and the coil-to-globule conformational transition mechanism laid the foundation of membrane permeabilizing polyanions. Furthermore, the research methods used by Tirrell et al. (such as pyrene fluorescent probes, interactions with model liposomal membranes, etc.) to evaluate the polymer conformation, critical $\mathrm{pH}$, and to quantify membrane permeability, have been widely adopted in the following studies within the field.

PPAA (or PPAAc in some literature) has been developed in the late 1990s (Murthy et al., 1999). Compared with PEAA, PPAA has a slightly longer pendant alkyl group on the monomer, which makes it more hydrophobic (Figure 1C). Murthy et al. used red blood cells, instead of simple liposomes, to evaluate the $\mathrm{pH}$ dependent membrane permeability of PPAA. Compared with liposomal membrane models, red blood cell membranes are more complicated, composed of not only lipids but also proteins and polysaccharides. The hemolytic activity, thus, was considered to better reflect the permeabilization capability toward biological membranes (Evans et al., 2013). PPAA showed higher hemolytic activity at acidic $\mathrm{pH}$ than PEAA without hemolytic activity at physiological $\mathrm{pH}$ at equivalent concentrations. It was speculated that PPAA could form pores on red blood cell membranes only at acidic $\mathrm{pH}$ which caused hemolysis (Murthy et al., 1999).

PPAA has been explored on mammalian cells, to enhance the gene transfection efficiency and to enhance the stability of cationic lipid gene vectors in serum (Cheung et al., 2001). The conjugation of PPAA on proteins, peptides, or antibodies by biotin-streptavidin ligation facilitated the intracellular delivery of these macromolecular cargos into the cytoplasm (Lackey et al., 2002; Albarran et al., 2011; Berguig et al., 2012). Other than chemical ligation, PPAA could form nano-polyplex by simply mixing with positively charged peptide cargos in PBS buffer (Evans et al., 2015a; Qiu et al., 2018). This approach was applicable to larger cationic cargos, including nucleic acids, gene editing ribonucleoproteins, and even nanoparticles (Evans et al., 2019). PPAA could also be formulated as polymer blends with poly(lactic-co-glycolic acid) (PLGA), to deliver antigens for T cell activation (Yang et al., 2017; Fernando et al., 2018). A detailed summary of PPAA related bioapplications is listed in Table $\mathbf{1 .}$

The mechanism of PPAA mediated endosomal escape is closely associated with endosomal acidification since the escape process was prone to $\mathrm{H}^{+}$-ATPase inhibition on the endosomal membrane (Jones et al., 2003; Evans et al., 2015a). Without endosomal acidification, the carboxylic acid groups of PPAA kept deprotonated, making the polymer negatively charged and non-lytic to endosomal membranes. This means the endosomal escape property of PPAA is dependent on the $\mathrm{pH}$-induced membrane permeabilization. Further studies by real-time imaging showed the intracellular delivery was correlated with galectin-8 (Gal8) recruitment, which confirms endosomal membrane damage by PPAA (Kilchrist et al., 2016). The damaged endosomes were subsequently autophaged by a "self-repaired" mechanism to avoid cell death caused by accidental endosomolytic reagents (Skowyra et al., 2018). This Gal8-mediated endosomal autophage suggests although PPAA caused damage to endosomal membranes to release the cargos intracellularly, the damage could be repaired by cells using an existing toolset.

PPAA functional derivatives, either by co-polymerization with other monomers or by changing the polymer architecture via end-to-end chemical ligations, have been widely reported for different intracellular delivery applications (Table 1). One of the most studied PPAA derivatives is the co-polymer of propylacrylic acid (PAA), dimethylaminoethyl methacrylate (DMAEMA), and butyl methacrylate (BMA). DMAEMA has a tertiary amine group, which is cationic at physiological $\mathrm{pH}$ (Agarwal et al., 2012). Therefore, it allows for binding with negatively charged DNA or RNA by electrostatic interaction. BMA has a butyl pendent group, which could enhance the hydrophobicity and membrane permeabilization capability at acidic $\mathrm{pH}$ (El-Sayed et al., 2005). A systematic investigation of the ratio of BMA in the final polymer suggested BMA-rich polymer not only showed higher hemolytic activity at $\mathrm{pH} 5.8$ but also elevated the gene delivery efficiency (Convertine et al., 2009). Further studies used DMAEMA and BMA copolymerized PAA for vaccine deliveries, by covalently conjugating antigen on a thiol-reactive pyridyl disulfide monomer (PDSEMA) (Wilson et al., 2013; Knight et al., 2019). Even without adjuvant, this carrier can promote antigen presenting on dendritic cells, and enhanced antigen-specific cytotoxic T cell responses (Keller et al., 2014).

Another common type of derivatives involves the incorporation of hydrophilic blocks in the copolymer, such as poly(N-(2-hydroxypropyl) methacrylamide) (HPMA), polyethylene glycol (PEG also named as PEO), or poly(oxyalkylene amine) (Jeffamine). The PEG block could 
TABLE 1 | Bioapplications of PPAA and its derivatives.

\begin{tabular}{|c|c|c|c|c|}
\hline Polymer & Therapeutic payloads & Loading method & Bioapplications & References \\
\hline PPAA & DNA plasmids, antisense DNA & $\begin{array}{l}\text { Mixture with cationic lipids } \\
\text { via electrostatic interaction }\end{array}$ & $\begin{array}{l}\text { Gene transfection in vitro } \\
\text { and in vivo }\end{array}$ & $\begin{array}{l}\text { Cheung et al., 2001; } \\
\text { Kyriakides et al., 2002; } \\
\text { Jones et al., 2003; Lee } \\
\text { et al., } 2006\end{array}$ \\
\hline PPAA & Antibodies and peptides & $\begin{array}{l}\text { Chemical ligation via } \\
\text { biotin-streptavidin }\end{array}$ & $\begin{array}{l}\text { Protein and peptide } \\
\text { intracellular delivery in vitro }\end{array}$ & $\begin{array}{l}\text { Lackey et al., 2002; } \\
\text { Albarran et al., 2011; } \\
\text { Berguig et al., } 2012\end{array}$ \\
\hline PPAA & $\begin{array}{l}\text { Peptide antigens with } \\
\text { oligolysine tails }\end{array}$ & Electrostatic interaction & $\begin{array}{l}\text { Induce cellular immunity as } \\
\text { cancer vaccines in vivo }\end{array}$ & Qiu et al., 2018 \\
\hline PPAA & Ovalbumin & $\begin{array}{l}\text { Blend with PLGA, double } \\
\text { emulsion }\end{array}$ & $\begin{array}{l}\text { Induce cellular immunity in } \\
\text { vitro }\end{array}$ & Yang et al., 2017 \\
\hline $\begin{array}{l}\text { Co-polymer of PAA, BMA, } \\
\text { DMAEMA }\end{array}$ & siRNA & Electrostatic interaction & Gene knockdown in vitro & $\begin{array}{l}\text { Convertine et al., 2009, } \\
\text { 2010; Palanca-Wessels } \\
\text { et al., } 2011\end{array}$ \\
\hline $\begin{array}{l}\text { Co-polymer of PAA, BMA, } \\
\text { DMAEMA }\end{array}$ & Ovalbumin & $\begin{array}{l}\text { Blend with PLGA, double } \\
\text { emulsion }\end{array}$ & $\begin{array}{l}\text { Induce humoral and cellular } \\
\text { immunity in vivo }\end{array}$ & $\begin{array}{l}\text { Tran et al., 2014; Zhan and } \\
\text { Shen, } 2015\end{array}$ \\
\hline $\begin{array}{l}\text { Co-polymer of PAA, and } \\
\text { PDSEMA }\end{array}$ & Ovalbumin & $\begin{array}{l}\text { Disulfide linkage with } \\
\text { PDSEMA }\end{array}$ & $\begin{array}{l}\text { Induce humoral and cellular } \\
\text { immunity in vivo }\end{array}$ & Foster et al., 2010 \\
\hline $\begin{array}{l}\text { Co-polymer of PAA, BMA, } \\
\text { PDSEMA, HPMA }\end{array}$ & siRNA or ovalbumin & $\begin{array}{l}\text { Disulfide linkage with } \\
\text { PDSEMA }\end{array}$ & $\begin{array}{l}\text { Gene knockdown or induce } \\
\text { cellular immunity in vivo }\end{array}$ & $\begin{array}{l}\text { Lundy et al., 2013; Keller } \\
\text { et al., } 2014\end{array}$ \\
\hline $\begin{array}{l}\text { Co-polymer of PAA, BMA, } \\
\text { PDSEMA, DMAEMA }\end{array}$ & $\begin{array}{l}\mathrm{CpG} \text { oligonucleotide (ODN) as } \\
\text { adjuvants and ovalbumin }\end{array}$ & $\begin{array}{l}\text { CpG ODN via electrostatic } \\
\text { interaction and ovalbumin } \\
\text { via disulfide linkage }\end{array}$ & $\begin{array}{l}\text { Induce humoral and cellular } \\
\text { immunity in vivo }\end{array}$ & $\begin{array}{l}\text { Wilson et al., 2013; Knight } \\
\text { et al., } 2019\end{array}$ \\
\hline
\end{tabular}

enhance polymer solubility by forming micelles and increase the resistance to serum proteins (Peddada et al., 2014; Porfiryeva et al., 2020). However, both PEG and Jeffamine conjugated PPAA showed reduced the $\mathrm{pH}$-dependent membrane-lytic activity (Peddada et al., 2009). This means the endosomal membrane disruption of these PEG and Jeffamine modified derivative polymers is less than PPAA itself. In the in vivo study, Jeffamine conjugated PPAA showed better overall gene delivery efficiency than PPAA, probably due to the enhanced serum stability (Peddada et al., 2014). These results suggest that selecting the polymer with the best endosomal escape capability does not always end up with the most optimal delivery performance in vivo. Instead, balancing the endosomal escape and serum stability in the PPAA derivative polymer is important to the delivery system.

Besides linear PPAA, hyperbranched and brush-like PPAA derivatives have been developed to study the effect of polymer architecture on $\mathrm{pH}$-dependent membrane permeabilizing activity. Introducing multivinyl branching monomer poly(ethylene glycol diacrylate) in the polymerization with PAA monomer generated hyperbranched PPAA, which showed lower hemolytic activity than linear PPAA at endosomal
$\mathrm{pH}$ conditions (Tai et al., 2012). This is probably due to the limitation of conformational changes from the branching points, which weakened the membrane interaction. Brush-like PPAA, synthesized by a "graft-to" strategy after polymerization by click chemistry, showed similar $\mathrm{pH}$-dependent hemolytic activity at the same mass concentration (Crownover et al., 2011).

\section{Copolymers of MAA or AA With Hydrophobic Moieties}

Similar to PPAA, the amphiphilic copolymers of MAA (or AA) with hydrophobic methacrylates have the coil-to-globule conformational transition, when the $\mathrm{pH}$ decreases from neutral to acidic ranges (Kusonwiriyawong et al., 2003; Yessine et al., 2003). These polymers have $\mathrm{pH}$-responsive carboxylate pendant groups from MAA, and hydrophobicity from non-ionizable methacrylates, such as BMA, dodecyl methacrylate (DMA), lauryl methacrylate (LMA), and cholesteryl methacrylate (CMA). Previous studies found that incorporating a small portion of hydrophobic monomers (i.e., 1\% DMA, 2\% CMA or 10\% LMA) in PMAA copolymers could enhance the interaction with lipid membranes significantly, compared with PMAA homopolymer (Cho et al., 2016; Sevimli et al., 2017; Wannasarit et al., 2019). 
However, a further increase of the hydrophobic moieties (i.e., $8 \%$ CMA and 40\% LMA) in the copolymer led to decreased solubility and enhanced supermolecular assembly in aqueous solutions, which in turn decreased the interaction between polymer and lipid membranes (Sevimli et al., 2012; Wannasarit et al., 2019). Therefore, it is critical to find the balance between the hydrophobic and hydrophilic monomers in the copolymer, to maximize the membrane association.

Regarding the applications of these MAA or AA-containing amphiphilic copolymers, a common approach is to decorate these polymers on the surface of liposomes and boost the delivery efficiency by enhancing the endosomal escape (Yessine et al., 2006; Yamazaki et al., 2017). Due to the anionic nature of these polymers, it is difficult to condensate DNA or RNA directly, but adding a cationic polymer in the formulation such as polylysine solves the problem by forming tertiary polyplexes via electrostatic interactions (Sevimli et al., 2013). A recent study indicated that these polymers can modify cell membranes by hydrophobic interactions and facilitate the delivery of cationic peptides (Dailing et al., 2020).

\section{Amphiphilic Carboxylated Polypeptides and Pseudopeptides}

Apart from acrylic and acrylate polymers, there are also amphiphilic carboxylated polypeptides reported for $\mathrm{pH}$ responsive membrane permeabilizing applications. These polypeptides are considered to be more biocompatible and biodegradable than their vinyl polymer counterparts (Akagi et al., 2006; Liu et al., 2019). A systematically investigated example is $\operatorname{poly}(\gamma$-glutamic acid) $(\gamma$ PGA $)$ and its derivatives grafted by different amino acids as pedant groups (Shima et al., 2014a). The protonation/deprotonation of glutamic acid units of PGA enabled the $\mathrm{pH}$-dependent conformation changes, while the hydrophobic amino acids (e.g., leucine, methionine, phenylalanine, valine, and tryptophan) enhanced the hydrophobicity and interaction with membranes. Unlike PPAA, $\gamma$ PGA with sufficient hydrophobic amino acid group grafting (53\% phenylalanine, $71 \%$ tryptophan, and $87 \%$ leucine) formed stable nanoparticle in PBS buffer, and the nanoparticles maintained $\mathrm{pH}$-responsive hemolytic activity similar to polymers (Akagi et al., 2010; Shima et al., 2014a). Furthermore, phenylalanine modified $\gamma$ PGA could encapsulate protein during its self-assembly and delivered protein payload to antigen presenting cells efficiently both in vitro and in vivo (Yoshikawa et al., 2008; Akagi et al., 2011). As a natural polymer derived from Bacillus, $\gamma$ PGA itself acted as an adjuvant for both innate and adaptive immunity activation and showed promising potentials for vaccine development (Uto et al., 2011). Interestingly, it was found that both the hemolytic activity at endosomal $\mathrm{pH}$, and the activation potential of antigen presenting cells increased proportionally to the hydrophobicity of the nanoparticles (Shima et al., 2013, 2014b).

A similar series of studies, using amphiphilic synthetic pseudopeptides namely poly (L-lysine isophthalamide) (PLP), also confirm that $\mathrm{pH}$-dependent membrane-permeabilizing capability could be adjusted by grafting amino acids with different hydrophobicity or alkyl chains (Eccleston et al., 2000; Chen et al., 2009, 2017). Increasing the hydrophobicity moieties or changing the polymer structure from linear to branched could increase the interaction with lipid membranes (Wang and Chen, 2017; Chen et al., 2020). Mechanistic insights suggest that phenylalanine modified PLP induced red blood cell membrane thinning of 35-40\% normal thickness at endosomal $\mathrm{pH}$, thus facilitating the transport of membrane-impermeable small molecular cargos (Lynch et al., 2011). Further real-time imaging showed that even large molecules such as FITC-labeled dextran of different molecular weights $(10-500 \mathrm{kDa})$ and green fluorescence protein could be delivered to different mammalian cells after co-incubation with phenylalanine modified PLP at $\mathrm{pH}$ 6.5 (Kopytynski et al., 2020). Such a convenient and flexible method provides a versatile platform for cell engineering ex vivo.

\section{DISCUSSIONS AND FUTURE OPPORTUNITIES}

Since the pioneering studies of PEAA with artificial lipid membranes, there have been almost 40 years of investigation into amphiphilic carboxylate polymers for endosomal escape applications. During these years, we have witnessed significant achievements in polymer synthesis and functionalization, which enables more control over the polymer structure. One of the biggest achievements is the development of controlled radical polymerization, especially reversible addition-fragmentation chain transfer (RAFT) polymerization (Fairbanks et al., 2015; Perrier, 2017). Because RAFT polymerization is compatible with carboxylate monomers and suitable at various conditions (such as in aqueous solutions or at ambient temperature), it has been widely adopted in the amphiphilic carboxylate polymers synthesis, including PPAA derivatives and copolymers of MAA or AA mentioned in the previous section (Convertine et al., 2009; Tai et al., 2012; Sevimli et al., 2013; Wannasarit et al., 2019; Dailing et al., 2020; Wang et al., 2020).

Meanwhile, the mechanism of polymer-mediated endosomal escape has been intensively explored, along with the advances in the basic understanding of the endocytosis process itself (Skowyra et al., 2018; Vermeulen et al., 2018; Brock et al., 2019; Patel et al., 2019; Pei and Buyanova, 2019). Molecular dynamics simulation and biophysical characterizations are commonly used to provide mechanistic insights into the interaction between polymers and artificial membranes at the molecular level (Scoppola and Schneck, 2018; Sen et al., 2018), while live imaging by fluorescence microscopy captures the endosomal escape on mammalian cells (Deprey et al., 2019). The imaging gives a direct visual presentation of the polymer and the endosomes labeled by fluorescent probes with a temporal-spatial resolution. Furthermore, incorporating different endocytosis inhibitors can help to investigate which endocytosis pathway the polymers utilize and whether endosomal acidification is required for the escape (Guo et al., 2015).

Notwithstanding the great achievements in both polymer synthesis tools and endosomal escape mechanism investigation, many fundamental issues remain to be addressed in this field. 
For example, the fate of the amphiphilic carboxylate polymers within the cells after the endosomal escape is rarely covered in the previous publications. It is not known whether the polymer carrier itself undergoes degradation in the cell, or gets expelled from the cell somehow. This issue is critical for biomedical applications, because of the long-term biosafety concerns. Further investigations are expected to result in an improved understanding of the degradative pathways of these polymers within the cells.

In summary, carboxylated amphiphilic polymers with $\mathrm{pH}$ responsive endosomolytic activities demonstrate promising potentials for the intracellular delivery of macromolecules. From a retrospective view, this field has continuously progressed with the application of new synthetic techniques, mechanistic understanding of endocytic trafficking, and better methods for endosomal escape characterization. Up to date, various designs have been made to adapt these polymers for biomedical applications, i.e., the delivery of antigens, genes, and therapeutic peptides. Nevertheless, it is still early to expect clinical translations, due to the lack of biodegradability and longterm biosafety concerns. It would require joint efforts from polymer chemists, biologists, and pharmaceutical scientists to

\section{REFERENCES}

Agarwal, S., Zhang, Y., Maji, S., and Greiner, A. (2012). PDMAEMA based gene delivery materials. Mater. Today 15, 388-393. doi: 10.1016/S1369-7021(12)70165-7

Akagi, T., Higashi, M., Kaneko, T., Kida, T., and Akashi, M. (2006). Hydrolytic and enzymatic degradation of nanoparticles based on amphiphilic poly $(\gamma$-glutamic acid)- graft - 1 -phenylalanine copolymers. Biomacromolecules 7, 297-303. doi: $10.1021 / \mathrm{bm} 050657 \mathrm{i}$

Akagi, T., Kim, H., and Akashi, M. (2010). pH-dependent disruption of erythrocyte membrane by amphiphilic poly(amino acid) nanoparticles. J. Biomater. Sci. Polym. Ed. 21, 315-328. doi: 10.1163/156856209X418519

Akagi, T., Shima, F., and Akashi, M. (2011). Intracellular degradation and distribution of protein-encapsulated amphiphilic poly(amino acid) nanoparticles. Biomaterials 32, 4959-4967. doi: 10.1016/j.biomaterials.2011.03.049

Albarran, B., Hoffman, A. S., and Stayton, P. S. (2011). Efficient intracellular delivery of a pro-apoptotic peptide with a pH-responsive carrier. React. Funct. Polym. 71, 261-265. doi: 10.1016/j.reactfunctpolym.2010. 09.008

Bazban-Shotorbani, S., Hasani-Sadrabadi, M. M., Karkhaneh, A., Serpooshan, V., Jacob, K. I., Moshaverinia, A., et al. (2017). Revisiting structure-property relationship of $\mathrm{pH}$-responsive polymers for drug delivery applications. J. Control. Release 253, 46-63. doi: 10.1016/j.jconrel.2017.02.021

Berguig, G. Y., Convertine, A. J., Shi, J., Palanca-Wessels, M. C., Duvall, C. L., Pun, S. H., et al. (2012). Intracellular delivery and trafficking dynamics of a lymphoma-targeting antibody-polymer conjugate. Mol. Pharm. 9, 3506-3514. doi: $10.1021 / \mathrm{mp} 300338 \mathrm{~s}$

Brock, D. J., Kondow-McConaghy, H. M., Hager, E. C., and Pellois, J.-P. (2019). Endosomal escape and cytosolic penetration of macromolecules mediated by synthetic delivery agents. Bioconjug. Chem. 30, 293-304. doi: 10.1021/acs.bioconjchem.8b00799

Bus, T., Traeger, A., and Schubert, U. S. (2018). The great escape: how cationic polyplexes overcome the endosomal barrier. J. Mater. Chem. B 6, 6904-6918. doi: 10.1039/C8TB00967H

Chen, J., Wang, K., Wu, J., Tian, H., and Chen, X. (2019). Polycations for gene delivery: dilemmas and solutions. Bioconjug. Chem. 30, 338-349. doi: 10.1021/acs.bioconjchem.8b00688 understand how polymers interact with endosomal membranes at the molecular level; how the endosomal escape happens at the cellular level; and finally the delivery in the complicated in vivo environment.

\section{AUTHOR CONTRIBUTIONS}

SW constructed the idea, designed the article, drafted and revised the manuscript. The author has agreed to publish the content of the work.

\section{FUNDING}

SW acknowledged the financial support from Finnish Culture Foundation (grant no. 00201144) and from Academy of Finland (decision no. 331106).

\section{ACKNOWLEDGMENTS}

The author thanks Helsinki University Library for covering the open access publication fees.

Chen, R., Eccleston, M. E., Yue, Z., and Slater, N. K. H. (2009). Synthesis and pHresponsive properties of pseudo-peptides containing hydrophobic amino acid grafts. J. Mater. Chem. 19, 4217-4224. doi: 10.1039/b902822f

Chen, S., Wang, S., Kopytynski, M., Bachelet, M., and Chen, R. (2017). Membraneanchoring, comb-like pseudopeptides for efficient, $\mathrm{pH}$-mediated membrane destabilization and intracellular delivery. ACS Appl. Mater. Interfaces 9, 8021-8029. doi: 10.1021/acsami.7b00498

Chen, S., Wu, L., Ren, J., Bemmer, V., Zajicek, R., and Chen, R. (2020). Comb-like pseudopeptides enable very rapid and efficient intracellular trehalose delivery for enhanced cryopreservation of erythrocytes. ACS Appl. Mater. Interfaces 12, 28941-28951. doi: 10.1021/acsami.0c03260

Cheung, C. Y., Murthy, N., Stayton, P. S., and Hoffman, A. S. (2001). A $\mathrm{pH}$-sensitive polymer that enhances cationic lipid-mediated gene transfer. Bioconjug. Chem. 12, 906-910. doi: 10.1021/bc0100408

Cho, S.-H., Hong, J. H., Noh, Y.-W., Lee, E., Lee, C.-S., and Lim, Y. T. (2016). Raspberry-like poly(andgamma;-glutamic acid) hydrogel particles for $\mathrm{pH}$-dependent cell membrane passage and controlled cytosolic delivery of antitumor drugs. Int. J. Nanomed. 11, 5621-5632. doi: 10.2147/IJN.S117862

Convertine, A. J., Benoit, D. S. W., Duvall, C. L., Hoffman, A. S., and Stayton, P. S. (2009). Development of a novel endosomolytic diblock copolymer for siRNA delivery. J. Control. Release 133, 221-229. doi: 10.1016/j.jconrel.2008.10.004

Convertine, A. J., Diab, C., Prieve, M., Paschal, A., Hoffman, A. S., Johnson, P. H., et al. (2010). pH-Responsive polymeric micelle carriers for siRNA drugs. Biomacromolecules 11, 2904-2911. doi: 10.1021/bm100652w

Crownover, E., Duvall, C. L., Convertine, A., Hoffman, A. S., and Stayton, P. S. (2011). RAFT-synthesized graft copolymers that enhance $\mathrm{pH}$-dependent membrane destabilization and protein circulation times. J. Control. Release 155, 167-174. doi: 10.1016/j.jconrel.2011.06.013

Cupic, K. I., Rennick, J. J., Johnston, A. P. R., and Such, G. K. (2019). Controlling endosomal escape using nanoparticle composition: current progress and future perspectives. Nanomedicine 14, 215-223. doi: 10.2217/nnm-2018-0326

Dailing, E. A., Kilchrist, K. V., Tierney, J. W., Fletcher, R. B., Evans, B. C., and Duvall, C. L. (2020). Modifying cell membranes with anionic polymer amphiphiles potentiates intracellular delivery of cationic peptides. ACS Appl. Mater. Interfaces 12, 50222-50235. doi: 10.1021/acsami.0c13304

Deirram, N., Zhang, C., Kermaniyan, S. S., Johnston, A. P. R., and Such, G. K. (2019). pH-Responsive polymer nanoparticles for drug delivery. Macromol. Rapid Commun. 40:1800917. doi: 10.1002/marc.201800917 
Deprey, K., Becker, L., Kritzer, J., and Plückthun, A. (2019). Trapped! a critical evaluation of methods for measuring total cellular uptake versus cytosolic localization. Bioconjug. Chem. 30, 1006-1027. doi: 10.1021/acs.bioconjchem.9b00112

Eccleston, M. E., Kuiper, M., Gilchrist, F. M., and Slater, N. K. H. (2000). pHresponsive pseudo-peptides for cell membrane disruption. J. Control. Release 69, 297-307. doi: 10.1016/S0168-3659(00)00316-3

El-Sayed, M. E. H., Hoffman, A. S., and Stayton, P. S. (2005). Rational design of composition and activity correlations for $\mathrm{pH}$-sensitive and glutathione-reactive polymer therapeutics. J. Control. Release 101, 47-58. doi: 10.1016/j.jconrel.2004.08.032

Eum, K. M., Langley, K. H., and Tirrell, D. A. (1989). Quasi-elastic and electrophoretic light scattering studies of the reorganization of dioleoylphosphatidylcholine vesicle membranes by poly(2-ethylacrylic acid). Macromolecules 22, 2755-2760. doi: 10.1021/ma00196a038

Evans, B. C., Fletcher, R. B., Kilchrist, K. V., Dailing, E. A., Mukalel, A. J., Colazo, J. M., et al. (2019). An anionic, endosome-escaping polymer to potentiate intracellular delivery of cationic peptides, biomacromolecules, and nanoparticles. Nat. Commun. 10:5012. doi: 10.1038/s41467-019-12906-y

Evans, B. C., Hocking, K. M., Kilchrist, K. V., Wise, E. S., Brophy, C. M., and Duvall, C. L. (2015a). Endosomolytic nano-polyplex platform technology for cytosolic peptide delivery to inhibit pathological vasoconstriction. ACS Nano 9, 5893-5907. doi: 10.1021/acsnano.5b00491

Evans, B. C., Hocking, K. M., Osgood, M. J., Voskresensky, I., Dmowska, J., Kilchrist, K. V., et al. (2015b). MK2 inhibitory peptide delivered in nanopolyplexes prevents vascular graft intimal hyperplasia. Sci. Transl. Med. 7:291 ra95. doi: 10.1126/scitranslmed.aaa4549

Evans, B. C., Nelson, C. E., Yu, S. S., Beavers, K. R., Kim, A. J., Li, H., et al. (2013). Ex vivo red blood cell hemolysis assay for the evaluation of $\mathrm{pH}$-responsive endosomolytic agents for cytosolic delivery of biomacromolecular drugs. J. Vis. Exp. e50166. doi: 10.3791/50166

Fairbanks, B. D., Gunatillake, P. A., and Meagher, L. (2015). Biomedical applications of polymers derived by reversible addition-fragmentation chain-transfer (RAFT). Adv. Drug Deliv. Rev. 91, 141-152. doi: 10.1016/j.addr.2015.05.016

Fernando, L. P., Lewis, J. S., Evans, B. C., Duvall, C. L., and Keselowsky, B. G. (2018). Formulation and characterization of poly(propylacrylic acid)/poly(lactic-co-glycolic acid) blend microparticles for $\mathrm{pH}$-dependent membrane disruption and cytosolic delivery. J. Biomed. Mater. Res. Part A 106, 1022-1033. doi: 10.1002/jbm.a.36298

Foster, S., Duvall, C. L., Crownover, E. F., Hoffman, A. S., and Stayton, P. S. (2010). Intracellular delivery of a protein antigen with an endosomal-releasing polymer enhances CD8 T-cell production and prophylactic vaccine efficacy. Bioconjug. Chem. 21, 2205-2212. doi: 10.1021/bc100204m

Guo, S., Zhang, X., Zheng, M., Zhang, X., Min, C., Wang, Z., et al. (2015). Selectivity of commonly used inhibitors of clathrin-mediated and caveolaedependent endocytosis of $\mathrm{G}$ protein-coupled receptors. Biochim. Biophys. Acta Biomembr. 1848, 2101-2110. doi: 10.1016/j.bbamem.2015.05.024

Jacobson, M. E., Wang-Bishop, L., Becker, K. W., and Wilson, J. T. (2019). Delivery of $5^{\prime}$-triphosphate RNA with endosomolytic nanoparticles potently activates RIG-I to improve cancer immunotherapy. Biomater. Sci. 7, 547-559. doi: 10.1039/C8BM01064A

Jones, R. A., Cheung, C. Y., Black, F. E., Zia, J. K., Stayton, P. S., Hoffman, A. S., et al. (2003). Poly(2-alkylacrylic acid) polymers deliver molecules to the cytosol by $\mathrm{pH}$-sensitive disruption of endosomal vesicles. Biochem. J. 372, 65-75. doi: 10.1042/bj20021945

Keller, S., Wilson, J. T., Patilea, G. I., Kern, H. B., Convertine, A. J., and Stayton, P. S. (2014). Neutral polymer micelle carriers with $\mathrm{pH}$-responsive, endosome-releasing activity modulate antigen trafficking to enhance CD8+ T cell responses. J. Control. Release 191, 24-33. doi: 10.1016/j.jconrel.2014.03.041

Kilchrist, K. V., Evans, B. C., Brophy, C. M., and Duvall, C. L. (2016). Mechanism of enhanced cellular uptake and cytosolic retention of MK2 inhibitory peptide nano-polyplexes. Cell. Mol. Bioeng. 9, 368-381. doi: 10.1007/s12195-016-0446-7

Knight, F. C., Gilchuk, P., Kumar, A., Becker, K. W., Sevimli, S., Jacobson, M. E., et al. (2019). Mucosal immunization with a pH-responsive nanoparticle vaccine induces protective $\mathrm{CD} 8+$ lung-resident memory $\mathrm{T}$ cells. ACS Nano 13, 10939-10960. doi: 10.1021/acsnano.9b00326
Kopytynski, M., Chen, S., Legg, S., Minter, R., and Chen, R. (2020). A versatile polymer-based platform for intracellular delivery of macromolecules. Adv. Ther. 3:1900169. doi: 10.1002/adtp.201900169

Kusonwiriyawong, C., van de Wetering, P., Hubbell, J. A., Merkle, H. P., and Walter, E. (2003). Evaluation of pH-dependent membrane-disruptive properties of poly(acrylic acid) derived polymers. Eur. J. Pharm. Biopharm. 56, 237-246. doi: 10.1016/S0939-6411(03)00093-6

Kyriakides, T. R., Cheung, C. Y., Murthy, N., Bornstein, P., Stayton, P. S., and Hoffman, A. S. (2002). pH-Sensitive polymers that enhance intracellular drug delivery in vivo. J. Control. Release 78, 295-303. doi: 10.1016/S0168-3659(01)00504-1

Lackey, C. A., Press, O. W., Hoffman, A. S., and Stayton, P. S. (2002). A biomimetic $\mathrm{pH}$-responsive polymer directs endosomal release and intracellular delivery of an endocytosed antibody complex. Bioconjug. Chem. 13, 996-1001. doi: $10.1021 / \mathrm{bc} 0100531$

Lee, L. K., Williams, C. L., Devore, D., and Roth, C. M. (2006). Poly(propylacrylic acid) enhances cationic lipid-mediated delivery of antisense oligonucleotides. Biomacromolecules 7, 1502-1508. doi: 10.1021/bm060114o

Liu, B., Zhang, Q., Zhou, F., Ren, L., Zhao, Y., and Yuan, X. (2019). Enhancing membrane-disruptive activity via hydrophobic phenylalanine and lysine tethered to poly(aspartic acid). ACS Appl. Mater. Interfaces 11, 14538-14547. doi: 10.1021 /acsami. 8 b22721

Lundy, B. B., Convertine, A., Miteva, M., and Stayton, P. S. (2013). Neutral polymeric micelles for RNA delivery. Bioconjug. Chem. 24, 398-407. doi: $10.1021 / \mathrm{bc} 300486 \mathrm{k}$

Lynch, A. L., Chen, R., and Slater, N. K. H. (2011). pH-responsive polymers for trehalose loading and desiccation protection of human red blood cells. Biomaterials 32, 4443-4449. doi: 10.1016/j.biomaterials.2011.02.062

Mukalel, A. J., Evans, B. C., Kilchrist, K. V., Dailing, E. A., Burdette, B., Cheung-Flynn, J., et al. (2018). Excipients for the lyoprotection of MAPKAP kinase 2 inhibitory peptide nano-polyplexes. J. Control. Release 282, 110-119. doi: 10.1016/j.jconrel.2018.04.045

Mukherjee, S., Ghosh, R. N., and Maxfield, F. R. (1997). Endocytosis. Physiol. Rev. 77, 759-803. doi: 10.1152/physrev.1997.77.3.759

Murthy, N., Robichaud, J. R., Tirrell, D. A., Stayton, P. S., and Hoffman, A. S. (1999). The design and synthesis of polymers for eukaryotic membrane disruption. J. Control. Release 61, 137-143. doi: 10.1016/S0168-3659(99)00114-5

Palanca-Wessels, M. C., Convertine, A. J., Cutler-Strom, R., Booth, G. C., Lee, F., Berguig, G. Y., et al. (2011). Anti-CD22 antibody targeting of $\mathrm{pH}$-responsive micelles enhances small interfering RNA delivery and gene silencing in lymphoma cells. Mol. Ther. 19, 1529-1537. doi: 10.1038/mt.2011.104

Patel, S., Kim, J., Herrera, M., Mukherjee, A., Kabanov, A. V., and Sahay, G. (2019). Brief update on endocytosis of nanomedicines. Adv. Drug Deliv. Rev. 144, 90-111. doi: 10.1016/j.addr.2019.08.004

Peddada, L. Y., Garbuzenko, O. B., Devore, D. I., Minko, T., and Roth, C. M. (2014). Delivery of antisense oligonucleotides using poly(alkylene oxide)-poly(propylacrylic acid) graft copolymers in conjunction with cationic liposomes. J. Control. Release 194, 103-112. doi: 10.1016/j.jconrel.2014.08.023

Peddada, L. Y., Harris, N. K., Devore, D. I., and Roth, C. M. (2009). Novel graft copolymers enhance in vitro delivery of antisense oligonucleotides in the presence of serum. J. Control. Release 140, 134-140. doi: 10.1016/j.jconrel.2009.08.008

Pei, D., and Buyanova, M. (2019). Overcoming endosomal entrapment in drug delivery. Bioconjug. Chem. 30, 273-283. doi: 10.1021/acs.bioconjchem.8b00778

Perrier, S. (2017). 50th anniversary perspective: RAFT polymerization-a user guide. Macromolecules 50, 7433-7447. doi: 10.1021/acs.macromol.7b00767

Porfiryeva, N. N., Moustafine, R. I., and Khutoryanskiy, V. V. (2020). PEGylated systems in pharmaceutics. Polym. Sci. Ser. C 62, 62-74. doi: $10.1134 / \mathrm{S} 181123822001004 \mathrm{X}$

Qiu, F., Becker, K. W., Knight, F. C., Baljon, J. J., Sevimli, S., Shae, D., et al. (2018). Poly(propylacrylic acid)-peptide nanoplexes as a platform for enhancing the immunogenicity of neoantigen cancer vaccines. Biomaterials 182, 82-91. doi: 10.1016/j.biomaterials.2018.07.052

Scoppola, E., and Schneck, E. (2018). Combining scattering and computer simulation for the study of biomolecular soft interfaces. Curr. Opin. Colloid Interface Sci. 37, 88-100. doi: 10.1016/j.cocis.2018. 06.008 
Scott, C. C., Vacca, F., and Gruenberg, J. (2014). Endosome maturation, transport, and functions. Semin. Cell Dev. Biol. 31, 2-10. doi: $10.1016 / \mathrm{j} . \mathrm{sem} c \mathrm{db} .2014 .03 .034$

Seki, K., and Tirrell, D. A. (1984). pH-Dependent complexation of poly(acrylic acid) derivatives with phospholipid vesicle membranes. Macromolecules 17, 1692-1698. doi: 10.1021/ma00139a009

Sen, S., Han, Y., Rehak, P., Vuković, L., and Král, P. (2018). Computational studies of micellar and nanoparticle nanomedicines. Chem. Soc. Rev. 47, 3849-3860. doi: 10.1039/C8CS00022K

Sevimli, S., Inci, F., Zareie, H. M., and Bulmus, V. (2012). Well-defined cholesterol polymers with ph-controlled membrane switching activity. Biomacromolecules 13, 3064-3075. doi: 10.1021/bm300846e

Sevimli, S., Knight, F. C., Gilchuk, P., Joyce, S., and Wilson, J. T. (2017). Fatty acidmimetic micelles for dual delivery of antigens and imidazoquinoline adjuvants. ACS Biomater. Sci. Eng. 3, 179-194. doi: 10.1021/acsbiomaterials.6b00408

Sevimli, S., Sagnella, S., Kavallaris, M., Bulmus, V., and Davis, T. P. (2013). Assessment of cholesterol-derived ionic copolymers as potential vectors for gene delivery. Biomacromolecules 14, 4135-4149. doi: 10.1021/bm4013088

Shima, F., Akagi, T., and Akashi, M. (2014a). Synthesis and preparation of nanoparticles composed of amphiphilic poly $(\gamma$-glutamic acid) with different hydrophobic side chains and their potential of membrane disruptive activity. Colloid Polym. Sci. 292, 2663-2671. doi: 10.1007/s00396-014-3303-Z

Shima, F., Akagi, T., and Akashi, M. (2014b). The role of hydrophobicity in the disruption of erythrocyte membrane by nanoparticles composed of hydrophobically modified poly( $\gamma$-glutamic acid). J. Biomater. Sci. Polym. Ed. 25, 203-210. doi: 10.1080/09205063.2013.848328

Shima, F., Akagi, T., Uto, T., and Akashi, M. (2013). Manipulating the antigen-specific immune response by the hydrophobicity of amphiphilic poly $(\gamma$-glutamic acid) nanoparticles. Biomaterials 34, 9709-9716. doi: 10.1016/j.biomaterials.2013.08.064

Skowyra, M. L., Schlesinger, P. H., Naismith, T. V., and Hanson, P. I. (2018). Triggered recruitment of ESCRT machinery promotes endolysosomal repair. Science. 360:eaar5078. doi: 10.1126/science.aar5078

Stewart, M. P., Langer, R., and Jensen, K. F. (2018). Intracellular delivery by membrane disruption: mechanisms, strategies, and concepts. Chem. Rev. 118, 7409-7531. doi: 10.1021/acs.chemrev.7b00678

Tai, H., Duvall, C. L., Hoffman, A. S., Stayton, P. S., and Wang, W. (2012). pHResponsive hyperbranched copolymers from one-pot RAFT copolymerization. Macromol. Mater. Eng. 297, 1175-1183. doi: 10.1002/mame.201200227

Thomas, J. L., Barton, S. W., and Tirrell, D. A. (1994). Membrane solubilization by a hydrophobic polyelectrolyte: surface activity and membrane binding. Biophys. J. 67, 1101-1106. doi: 10.1016/S0006-3495(94)80575-2

Thomas, J. L., and Tirrell, D. A. (1992). Polyelectrolyte-sensitized phospholipid vesicles. Acc. Chem. Res. 25, 336-342. doi: 10.1021/ar00020a003

Tran, K. K., Zhan, X., and Shen, H. (2014). Polymer blend particles with defined compositions for targeting antigen to both class I and II antigen presentation pathways. Adv. Healthc. Mater. 3, 690-702. doi: 10.1002/adhm.201300306

Uto, T., Akagi, T., Yoshinaga, K., Toyama, M., Akashi, M., and Baba, M. (2011). The induction of innate and adaptive immunity by biodegradable poly $(\gamma-$ glutamic acid) nanoparticles via a TLR4 and MyD88 signaling pathway. Biomaterials 32, 5206-5212. doi: 10.1016/j.biomaterials.2011.03.052

van Haasteren, J., Li, J., Scheideler, O. J., Murthy, N., and Schaffer, D. V. (2020). The delivery challenge: fulfilling the promise of therapeutic genome editing. Nat. Biotechnol. 38, 845-855. doi: 10.1038/s41587-020-0565-5

Vermeulen, L. M. P., De Smedt, S. C., Remaut, K., and Braeckmans, K. (2018). The proton sponge hypothesis: fable or fact? Eur. J. Pharm. Biopharm. 129, 184-190. doi: 10.1016/j.ejpb.2018.05.034
Wang, S. (2018). Synthesis and Characterisation of Stimuli-responsive Amino Acidbased Polymeric Materials for Drug Delivery. Imperial College London, London, United Kingdom.

Wang, S., and Chen, R. (2017). pH-Responsive, lysine-based, hyperbranched polymers mimicking endosomolytic cell-penetrating peptides for efficient intracellular delivery. Chem. Mater. 29, 5806-5815. doi: 10.1021/acs.chemmater.7b00054

Wang, S., Wannasarit, S., Figueiredo, P., Molinaro, G., Ding, Y., Correia, A., et al. (2020). Intracellular delivery of budesonide and polydopamine coloaded in endosomolytic poly(butyl methacrylate- co -methacrylic acid) grafted acetalated dextran for macrophage phenotype switch from M1 to M2. Adv. Ther.4:2000058. doi: 10.1002/adtp.202000058

Wannasarit, S., Wang, S., Figueiredo, P., Trujillo, C., Eburnea, F., Simón-Gracia, L., et al. (2019). A virus-mimicking pH-responsive acetalated dextran-based membrane-active polymeric nanoparticle for intracellular delivery of antitumor therapeutics. Adv. Funct. Mater. 29:1905352. doi: 10.1002/adfm.201905352

Wilson, J. T., Keller, S., Manganiello, M. J., Cheng, C., Lee, C.-C., Opara, C., et al. (2013). pH-Responsive nanoparticle vaccines for dual-delivery of antigens and immunostimulatory oligonucleotides. ACS Nano 7, 3912-3925. doi: $10.1021 / \mathrm{nn} 305466 \mathrm{z}$

Yamazaki, N., Sugimoto, T., Fukushima, M., Teranishi, R., Kotaka, A., Shinde, C., et al. (2017). Dual-stimuli responsive liposomes using pH- and temperaturesensitive polymers for controlled transdermal delivery. Polym. Chem. 8, 1507-1518. doi: 10.1039/C6PY01754A

Yang, L., Bracho-Sanchez, E., Fernando, L. P., Lewis, J. S., Carstens, M. R., Duvall, C. L., et al. (2017). Poly(2-propylacrylic acid)/poly(lactic-co-glycolic acid) blend microparticles as a targeted antigen delivery system to direct either CD4+ or CD8+ T cell activation. Bioeng. Transl. Med. 2, 202-211. doi: $10.1002 / \mathrm{btm} 2.10068$

Yessine, M. A., Lafleur, M., Meier, C., Petereit, H.-U., and Leroux, J.-C. (2003). Characterization of the membrane-destabilizing properties of different $\mathrm{pH}$ sensitive methacrylic acid copolymers. Biochim. Biophys. Acta Biomembr. 1613, 28-38. doi: 10.1016/S0005-2736(03)00137-8

Yessine, M. A., Meier, C., Petereit, H. U., and Leroux, J. C. (2006). On the role of methacrylic acid copolymers in the intracellular delivery of antisense oligonucleotides. Eur. J. Pharm. Biopharm. 63, 1-10. doi: 10.1016/j.ejpb.2005.10.010

Yoshikawa, T., Okada, N., Oda, A., Matsuo, K., Matsuo, K., Kayamuro, H., et al. (2008). Nanoparticles built by self-assembly of amphiphilic $\gamma$-PGA can deliver antigens to antigen-presenting cells with high efficiency: a new tumor-vaccine carrier for eliciting effector T cells. Vaccine 26, 1303-1313. doi: $10.1016 /$ j.vaccine.2007.12.037

Zhan, X., and Shen, H. (2015). Programming the composition of polymer blend particles for controlled immunity towards individual protein antigens. Vaccine 33, 2719-2726. doi: 10.1016/.j.vaccine.2015.03.018

Conflict of Interest: The author declares that the research was conducted in the absence of any commercial or financial relationships that could be constructed as a potential conflict of interest.

Copyright (c) 2021 Wang. This is an open-access article distributed under the terms of the Creative Commons Attribution License (CC BY). The use, distribution or reproduction in other forums is permitted, provided the original author(s) and the copyright owner(s) are credited and that the original publication in this journal is cited, in accordance with accepted academic practice. No use, distribution or reproduction is permitted which does not comply with these terms. 